\title{
Hypothalamic hamartomas. Part 2. Surgical considerations and outcome
}

\author{
Sandeep Mittal, M.D., F.R.C.S.C., ${ }^{1}$ Monika Mittal, M.D., ${ }^{1}$ José Luis Montes, M.D., ${ }^{2}$ \\ Jean-Pierre Farmer, M.D., F.R.C.S.C., ${ }^{2}$ and Frederick Andermann, M.D., F.R.C.P.C. ${ }^{3}$ \\ ${ }^{1}$ Department of Neurosurgery, Comprehensive Epilepsy Center, Wayne State University, Detroit Medical \\ Center, Detroit, Michigan; ${ }^{2}$ Department of Neurosurgery, Montreal Children's Hospital, McGill University, \\ Montreal, Quebec, Canada; and ${ }^{3}$ Department of Neurology and Neurosurgery, Montreal Neurological \\ Institute, McGill University, Montreal, Quebec, Canada
}

\begin{abstract}
Hypothalamic hamartomas are uncommon developmental heterotopic masses composed of an intermixed array of neurons, glia, and myelinated fibers closely associated with the mammillary bodies. Gelastic seizures, the hallmark feature of hypothalamic hamartomas, commonly present in early childhood. However, patients usually also display a disabling clinical syndrome, which may include various other types of refractory seizures with secondary generalization together with progressive cognitive, behavioral, and psychiatric dysfunction. The hamartoma itself has been unequivocally shown to be intrinsically epileptogenic. Over the past 2 decades there has been considerable effort to develop neurosurgical techniques to treat the epileptic syndrome effectively as well as to improve the neurocognitive and behavioral outcome.
\end{abstract}

(http://thejns.org/doi/abs/10.3171/2013.3.FOCUS1356)

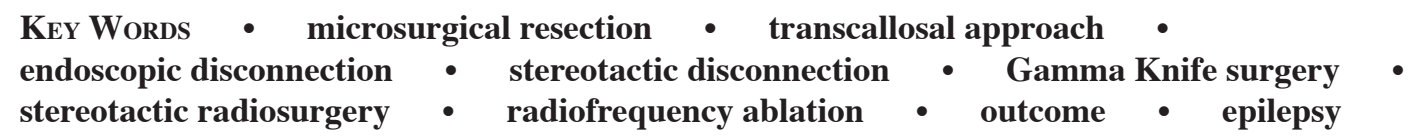

I $\mathrm{N}$ this review we discuss the various microsurgical approaches used to remove the hamartoma. In addition, we review the experience with less invasive surgical strategies, such as neuroendoscopic disconnection and SRS. These techniques have also been shown to yield good outcome in seizure control and improvements in behavior, cognition, and overall development. Younger children may particularly benefit from aggressive neurosurgical management in an effort to reduce or prevent the sequelae commonly associated with $\mathrm{HHs}$.

Patients with $\mathrm{HH}$ suffer from devastating medically intractable epilepsy as well as substantial and progressive behavioral, cognitive, and psychiatric dysfunction. Hence, a lot of effort has been given in developing new and refining existing surgical techniques for the treatment of these problematic diencephalic lesions. In 1967, North-

\footnotetext{
Abbreviations used in this paper: $\mathrm{CPP}=$ central precocious puberty; DBS = deep brain stimulation; DI = diabetes insipidus; GKS = Gamma Knife surgery; $\mathrm{HH}=$ hypothalamic hamartoma; LINAC $=$ linear accelerator; SRS $=$ stereotactic radiosurgery; VNS = vagal nerve stimulator.
}

field and Russell ${ }^{48}$ performed the first successful removal of an HH causing CPP. In 1969, Paillas et al. ${ }^{49}$ described the clinical, radiographic, and histological findings in a patient who underwent microsurgical excision of an $\mathrm{HH}$. Over the next 2 decades, a handful of other investigators reported their efforts to control the gelastic seizures by excision of the HH. ${ }^{46,57,58,69}$ Interest in the surgical treatment of HHs expanded noticeably in the 1990s as a result of the widespread availability of high-resolution MRI, enabling accurate identification of HHs.

In this review we will discuss the different microsurgical strategies used in the treatment of HHs and associated refractory gelastic seizures. In addition, we will review alternatives to open surgery such as endoscopic disconnection of the $\mathrm{HH}$ and other less invasive techniques, including stereotactic radiosurgery and radiofrequency thermocoagulation. Recent advances and efforts have resulted in minimizing surgical morbidity with improved outcomes. The clinical, electrophysiological, and neuroimaging characteristics of HHs have been outlined in Part I of this 2-part review. ${ }^{41}$ 


\section{Microsurgical Resection of HH}

Surgical intervention appears to provide the best opportunity for achieving seizure freedom and halting (and perhaps reversing) the progressive decline in neurocognitive function as well as improving the coexisting behavioral and psychiatric syndrome. Broadly speaking, microsurgical approaches can be divided into those that reach the diencephalic mass from below and those that reach it from above. ${ }^{65}$ Others advocate that disconnection from the mammillary bodies rather than complete excision of the $\mathrm{HH}$ is sufficient to eliminate seizures, and that this procedure carries less surgical morbidity. Still others believe that a strictly noninvasive modality such as SRS is the optimal choice for managing these difficult lesions. Ultimately, the choice of surgical approach should be tailored to each patient depending on the size of the hamartoma, its anatomical relationship to the hypothalamus and surrounding neurovascular structures, the age of the patient, and the surgeon's experience and comfort with the operative technique. ${ }^{76}$

\section{Pterional Approach}

Given the familiarity of conventional frontotemporal and pterional approaches, it is not surprising that these techniques were commonly used in the initial clinical series reporting microsurgical resection of HHs (Fig. 1). ${ }^{36,47}$ Some authors reported that addition of a subfrontal, subtemporal, transsylvian, or other skull base access could facilitate excision of the hypothalamic lesion. ${ }^{23,39,40} \mathrm{Al}-$ though it does provide the shortest and most direct route to the suprasellar cistern, the pterional approach does
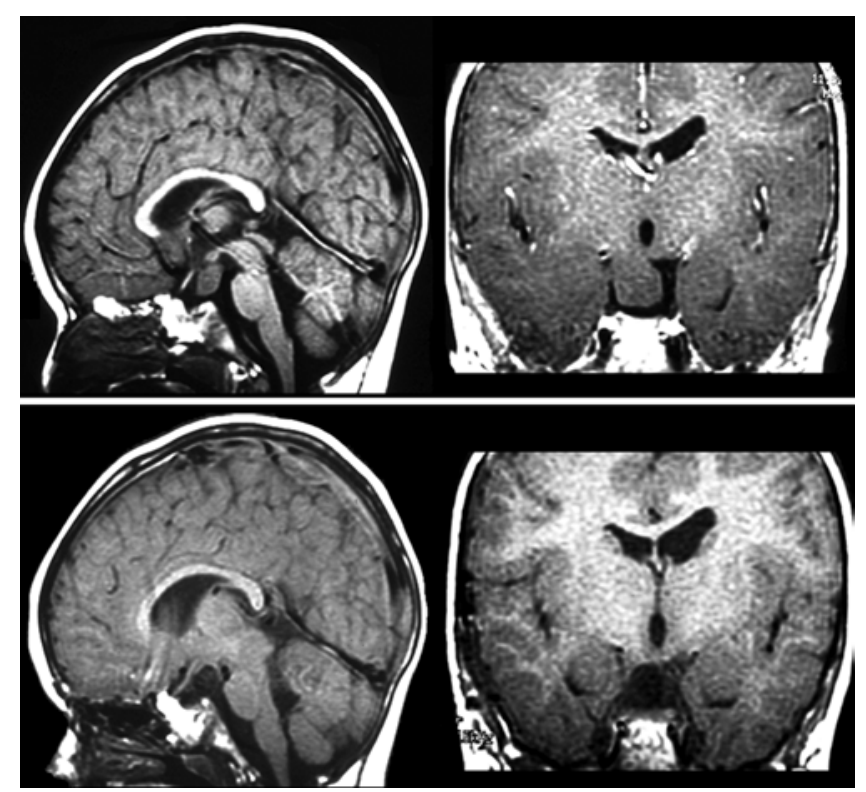

FIG. 1. Patient treated via the pterional approach. This 3-year-old boy presented with gelastic seizures at the age of 1 year. He developed myoclonic spasms at 19 months, with regression of fine motor tasks accompanied by psychomotor and speech retardation. Sagittal and coronal MRIs show a Delalande and Fohlen Type I pedunculated HH (upper panel). Postoperative MRIs obtained following a pterional craniotomy for resection of the hamartoma (lower panel). The patient was seizure free after surgery and had marked improvement in behavior. have inherent limitations. The narrow surgical corridor between the internal carotid artery, optic nerve and chiasm, third cranial nerve, and infundibulum limits access to the third ventricle and the intraventricular component of the HH. Identifying the margins of the hamartoma is often challenging, particularly if it is broadly attached to the hypothalamus and mammillary bodies. Using the pterional approach to resect the $\mathrm{HH}$, Palmini et al. reported that 3 of their 13 patients achieved seizure freedom, and $\mathrm{a}>90 \%$ reduction in seizure frequency was noted in the remaining 10 children. ${ }^{51}$ All patients demonstrated significantly improved behavior and cognition following microsurgical excision of the $\mathrm{HH}$. However, significant morbidity occurred in 7 patients in whom the transsylvian approach was used, including transient third nerve palsy, thalamocapsular infarcts, postoperative central DI, and hyperphagia (Fig. 2). ${ }^{51}$

The Barrow group followed 10 patients who underwent either an orbitozygomatic approach alone or combined with a transventricular endoscopic excision of the HH. ${ }^{1}$ After a mean follow-up of 37 months, 4 patients became seizure free. All 4 had total or near-total resection of their lesions with complete disconnection of the hamartoma. Cognitive outcome was either improved or unchanged in 8 patients, and 2 had improvements in behavior. Nine of the 10 patients' families reported some improvement in quality of life. Complications included increased appetite, DI, visual field deficit, and capsular infarct. One patient required ligation of the supraclinoid portion of the internal carotid artery, but fortunately had good collateral flow and no ensuing deficits. Based on their case series, these authors concluded that HHs attached below the third ventricle (Delalande and Fohlen Type I) would benefit from the orbitozygomatic approach, but that most other patients with $\mathrm{HH}$ would benefit from either a superior approach or from endoscopic or stereotactic radiosurgical procedures.

Overall, despite excellent outcomes in terms of seizure control, the frontotemporal approach resulted in major complications. These suboptimal results created a need to develop alternate surgical strategies to improve seizure freedom rates while limiting surgery-related morbidity. ${ }^{35,42}$ Nevertheless, a pterional approach seems best for targeting pedunculated HHs that cause CPP. Even a
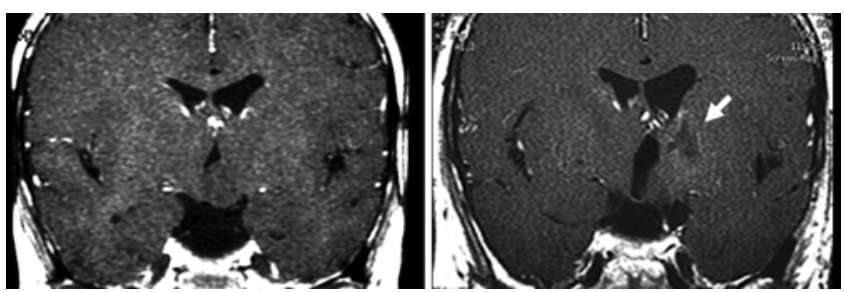

FIG. 2. Complications of pterional approach. This 7-year-old boy, in whom gelastic seizures had been diagnosed at the age of 5 months, developed worsening speech and language difficulties along with aggressive behavior. Preoperative MRI showed a Delalande and Fohlen Type II intrahypothalamic HH (left). The patient was seizure free and had significantly improved behavior after microsurgical resection of the hamartoma was performed using a pterional approach. However, he developed persistent right hemiparesis as a result of a left thalamocapsular infarct (arrow, right). 


\section{Surgical approaches and outcomes in $\mathrm{HHs}$}

partial resection has been shown to relieve the endocrinological disturbance. ${ }^{25}$ Pedunculated $\mathrm{HHs}$ seem more amenable to complete resection than sessile ones.

\section{Transcallosal Approach}

In 2001, Rosenfeld et al. ${ }^{68}$ first reported their experience using an anterior transcallosal, transseptal, interforniceal approach to remove HHs through the third ventricle. Their approach consisted of a small (15-20 $\mathrm{mm}$ in length) postgenual callosotomy followed by midline transseptal dissection and separation of the fornices, which allowed entry through the roof of the third ventricle with subsequent removal and/or disconnection of the $\mathrm{HH}$ (Fig. 3). ${ }^{67}$ This elegant technique offers not only an exceptional intraventricular view of the hamartoma from above, but compared with the approaches from below, allows adequate debulking or disconnection of the $\mathrm{HH}$ while reducing risk of injury to the mammillary bodies, pituitary stalk, and optic chiasm (Fig. 4). Moreover, the incidence of cerebral infarction and oculomotor nerve palsy is greatly reduced by avoiding manipulation of the neurovascular structures in the suprasellar cistern and interpeduncular fossa. However, there is an inherent risk of septal, forniceal, or mammillary body injury resulting in short-term memory problems. The risk of postsurgi- cal memory deficits can be reduced by using a modified subchoroidal approach instead of splitting the fornices. ${ }^{9}$

In 2003, the Melbourne group reported their results after using the anterior transcallosal, transseptal, interforniceal approach in 29 patients followed for a mean of 30 months. ${ }^{27}$ They achieved a complete or near-complete $(>95 \%)$ resection in 18 patients $(62 \%)$. Of the 29 patients, $15(52 \%)$ were seizure free and another $7(24 \%)$ had a > $90 \%$ decrease in frequency of seizures following surgery. Complications included thalamic infarction, increased appetite, and short-term memory deficits. ${ }^{66}$ Cognitive outcomes studied in 6 older patients (mean age 24 years) in a follow-up study showed mild improvement in perceptual and visuospatial function, but there was no evidence of improvement in multidomain cognition, which had been seen in younger patients. ${ }^{4}$ Three of the patients had memory deterioration postoperatively, most likely due to damage to the fornices or the mammillary bodies during surgery. The authors concluded that SRS may be the preferable approach for older adolescents and adults. ${ }^{4}$

After their initial study in 10 patients, ${ }^{18}$ in 2006 the team at the Barrow Neurological Institute published surgical outcomes in 26 patients and demonstrated a direct relationship between the extent of $\mathrm{HH}$ excision and seizure outcome. ${ }^{44}$ Fourteen $(54 \%)$ of the 26 patients were seizure
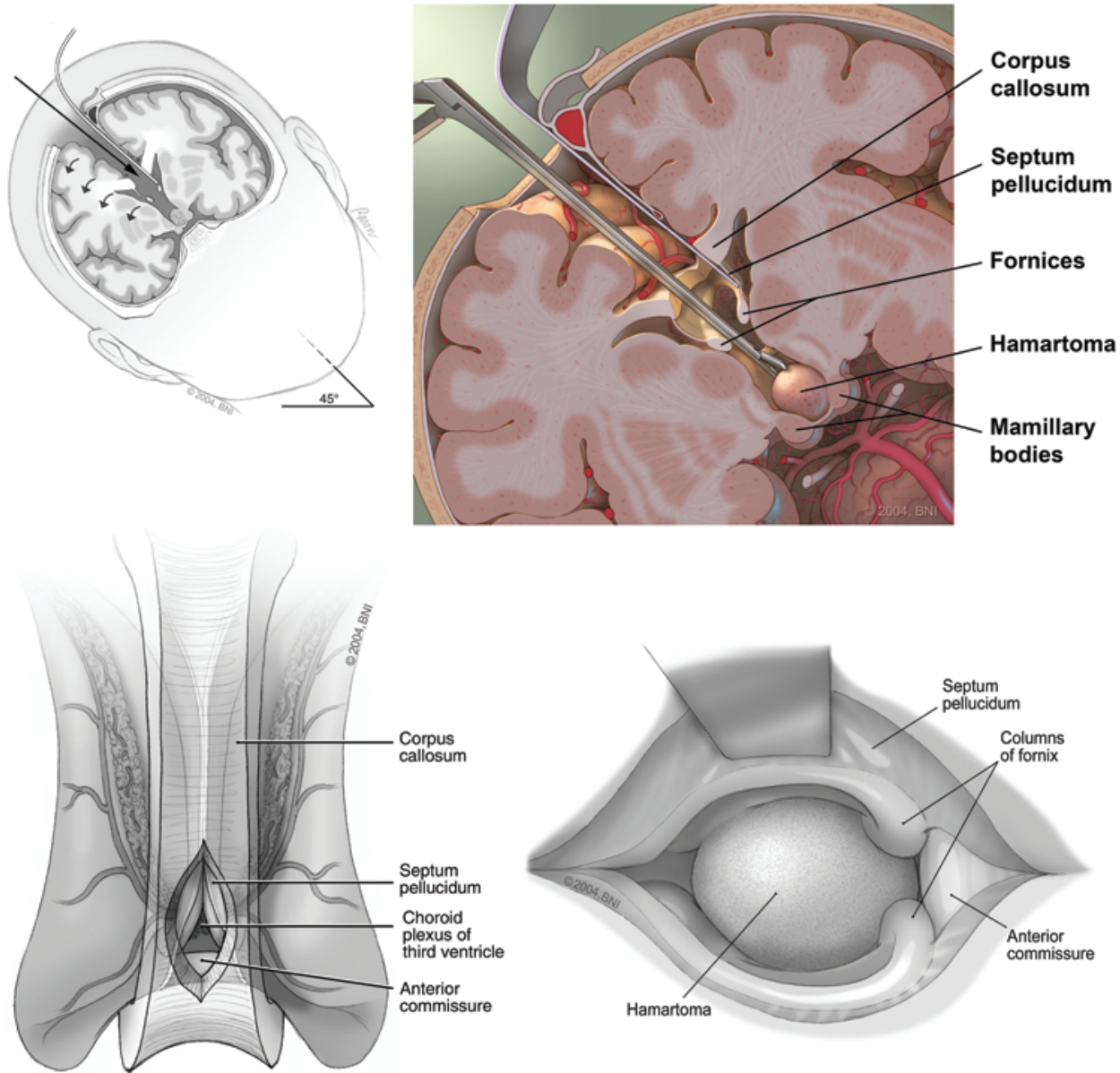

FIG. 3. Illustration of transcallosal transseptal interforniceal approach used for resection of HHs, with relevant neuroanatomical structures. Adapted from Wait et al: Neurosurg Focus 30(2):E2, 2011. Modified with permission from Barrow Neurological Institute. 

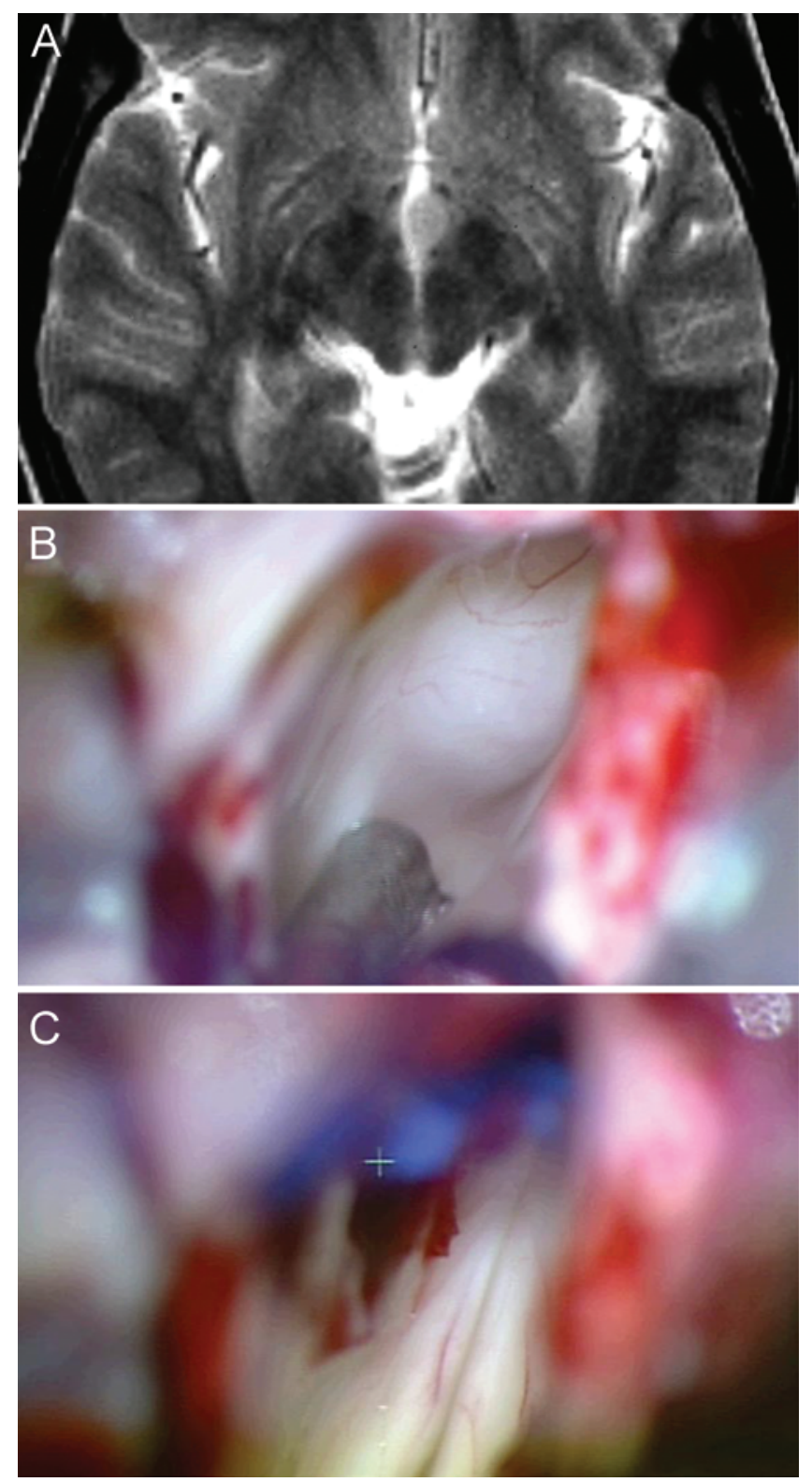

FIG. 4. Patient treated via the transcallosal approach. Axial T2weighted MRI showing a small Delalande and Fohlen Type II HH (A). Intraoperative photographs obtained following a transcallosal interforniceal approach before $(\mathbf{B})$ and after $(\mathbf{C})$ microsurgical resection of the mass.

free and another $9(35 \%)$ had $>90 \%$ reduction in seizure frequency. Improved behavior and cognition was noted in $23(88 \%)$ and $17(65 \%)$ patients, respectively. Fifteen $(58 \%)$ experienced memory disturbance after surgery, but this only persisted in 2 (8\%). One patient had persisting hypothyroidism and another had central DI requiring hormone replacement therapy. The investigators demonstrated a correlation between completeness of excision of the $\mathrm{HH}$ and seizure freedom. They also noted a strong inverse correlation between the duration of epilepsy and volume of $\mathrm{HH}$ and the probability of a seizure-free outcome. Whereas complete resection of larger hamartomas can be accomplished safely in younger patients by using the transcallo- sal interforniceal approach, the authors noted that in older patients there is an increased risk of memory impairment from forniceal injury because the leaves of the septum pellucidum are not as easily separated. ${ }^{44}$

Yao and colleagues ${ }^{80}$ reviewed their series of 37 patients with $\mathrm{HH}$ who underwent an interhemispheric approach. They concluded that the transcallosal interforniceal approach is effective in controlling gelastic seizures and has few complications. The most common adverse effect of surgery was electrolyte imbalance. In the past few years, several other groups have reported good outcomes with the anterior transcallosal, transseptal, interforniceal approach.

\section{Transtemporal, Transchoroidal, Transamygdala Approach}

Hamlat and colleagues ${ }^{26}$ recently described their experience with a transamygdala extension of a transtemporal, transchoroidal approach for radical resection of 5 suprasellar, retrochiasmatic, diencephalomesencephalic lesions, including $1 \mathrm{HH}$. This approach may be valuable for large HHs occupying the interpeduncular cistern.

\section{Endoscopic Transventricular Approach}

In 2002, Akai et al. ${ }^{3}$ first reported using an endoscope for transventricular biopsy of an $\mathrm{HH}$ in a 5-yearold girl with gelastic seizures. The hamartoma was then treated with stereotactic radiosurgery by using a LINAC. Unfortunately, the patient's seizure and behavioral problems remained unchanged for 6 months. She eventually underwent a partial resection with laser coagulation of the $\mathrm{HH}$ in which a neuroendoscopic approach was used. Postoperatively, a significant reduction in the frequency of her seizures was noted together with marked improvement of her violent behavior.

In 2006, the Barrow group published their results using endoscopy for HHs. ${ }^{63}$ In their series, 44 patients underwent an endoscopic transventricular approach in which frameless stereotaxy was used for resection of the $\mathrm{HH}$ that was causing refractory gelastic seizures. Of the 14 patients $(31.8 \%)$ who had complete resection, 13 became seizure free following surgery. The remaining 30 patients underwent an endoscopic disconnection rather than resection of the $\mathrm{HH}$ (see below).

Cappabianca and colleagues ${ }^{10}$ provided an excellent review of the use of neuroendoscopy to treat intraventricular lesions. They noted that not all patients with HHs are ideal candidates for endoscopic resection. These authors emphasized that this approach should be considered for small HHs with a unilateral attachment to the hypothalamic wall. Furthermore, they cautioned that it is imperative that a space between the bottom of the hamartoma and the pial surface of the interpeduncular cistern must exist for an endoscopic approach to remove HHs to be considered. Likewise, they reported that a working distance of at least $6 \mathrm{~mm}$ should be present between the top of the $\mathrm{HH}$ and the roof of the third ventricle.

Clearly, no single microsurgical approach can provide access to the entire variety of HHs. Surgical approaches must be carefully chosen based on the site, type of $\mathrm{HH}$ (sessile or pedunculated), and its extensions. Over 
the years, however, the transcallosal, interforniceal approach has become the preferred route for resection and/ or disconnection of HHs in many epilepsy surgery centers, including ours.

\section{Open and Endoscopic Disconnection of HH}

Delalande and Fohlen ${ }^{15}$ hypothesized that disconnection (without excision) of the $\mathrm{HH}$ could be sufficient to isolate the intrinsically epileptogenic lesion and thereby result in good seizure outcomes. In 2003 they published their series of patients who underwent disconnection of the intraventricular component of the hamartoma. ${ }^{19}$ Of 18 patients, 14 underwent open surgical disconnection, 3 had a pure endoscopic disconnection procedure, and 1 had complete excision of the hamartoma. Altogether, nearly half of the patients ( 8 of 17) were seizure free after open and/or endoscopic disconnection of the hypothalamic mass. Moreover, the vast majority of patients attained marked improvement in social and behavioral outcomes. Surgical complications included ischemic stroke in 2 patients, meningitis in 1 , and transient DI in 2 cases. ${ }^{19}$

In 2004, Choi et al. ${ }^{12}$ published their initial results with endoscopic disconnection in 4 patients with $\mathrm{HH}$ related refractory seizures. In their follow-up study,$^{73}$ the Korean group reported on 14 patients harboring a sessile $\mathrm{HH}, 11$ of which were treated with endoscopic disconnection (primary treatment in 9 patients, and 2 others underwent surgery following initial GKS). Six patients became immediately seizure free and 4 others had a good outcome (Engel Class II). Two patients underwent endoscopic disconnection following radiosurgery; their gelastic seizures disappeared after the disconnection. All 11 patients had placement of a single depth electrode in the $\mathrm{HH}$ prior to and after the endoscopic disconnection. These authors confirmed (via the results obtained from the depth electrodes) the intrinsic epileptogenesis of HHs, which was contained by hindering the propagation of the epileptic activity via simple disconnection of the $\mathrm{HH}$. Overall, these authors noted that patients with smaller hamartomas had better overall outcome and that an endoscopic approach offered a safe and effective alternative.

In a follow-up paper, ${ }^{45}$ the Barrow group reported the long-term results in 37 patients who underwent endoscopic disconnection and resection for $\mathrm{HH}$. Complete disconnection and resection was achieved in 12 patients. Twenty-six patients $(70.3 \%)$ had $>90 \%$ reduction in seizure frequency (18 of 37 [48.6\%] became seizure free), 8 patients $(21.6 \%)$ had between $50 \%$ and $90 \%$ reduction in frequency, 2 remained unchanged, and 1 worsened clinically. The most significant postoperative morbidity was persistent short-term memory loss in 3 patients. Two additional patients had transient memory impairment. Of the 12 patients who underwent both disconnection and complete resection, 8 (67\%) became seizure free.

Similar results were obtained by Shim and colleagues, ${ }^{73}$ who performed endoscopic disconnection in 11 patients by using neuronavigation guidance. Stabell et al. ${ }^{74}$ noted a significant decline in cognitive function (decrease in verbal IQ, immediate and delayed recall, and color naming) in a young girl with $\mathrm{HH}$ who underwent incomplete endoscopic disconnection of the hamartoma. She also had persistent hemiparesis and oculomotor paresis after surgery.

Again, not all lesions are amenable to endoscopic disconnection. The feasibility of successful disconnection depends on a number of factors, including the plane and extent of attachment of the HH to the hypothalamus. ${ }^{14}$ Some large lesions may require a multistep approach in which several disconnective procedures are used, or a combination of microsurgical resection and endoscopic disconnection. They noted that patients with large HHs (> $15 \mathrm{~mm}$ in diameter) had poorer seizure outcomes.

Open and endoscopic disconnection surgery is a generally safe and effective surgical option for small, sessile HHs. However, completeness of the disconnection and/ or removal appears to correlate with improved rates of seizure freedom. Again, a tailored approach based on the radiographic characteristics of the $\mathrm{HH}$ is recommended. However, as highlighted by Stabell and colleagues, ${ }^{74}$ even this "less invasive" treatment modality may result in longterm neurological and cognitive deficits.

\section{Stereotactic Radiosurgery}

The elegance of selective targeting of the deep-seated mass in a minimally invasive manner together with the important risks associated with various surgical approaches prompted the use of SRS to treat gelastic seizures related to HHs. Both GKS and LINAC-based radiosurgery have been used by several groups. Additionally, brachytherapy by means of stereotactic implantation of radioactive sources within the hamartoma has been used by some investigators.

\section{Gamma Knife Surgery}

The group in Marseille pioneered the use of SRS in treating patients with intractable mesial temporal lobe epilepsy. ${ }^{61}$ The initial promising results obtained in these patients provided compelling support for the use of SRS in patients with HHs. Over the past 15 years, numerous centers have reported their experience with using GKS for its specific antiepileptic effect in patients with $\mathrm{HH}$ who were suffering from intractable epilepsy.

Successful treatment of $\mathrm{HH}$-associated gelastic seizures by using GKS was first reported by Arita et al. ${ }^{6}$ in 1998. Their patient, a 25-year-old man with a small $\mathrm{HH}$ and long-standing history of medically refractory gelastic and tonic-clonic seizures, was treated with a dose of 18 Gy to the $50 \%$ isodose line. His seizures abated 3 months after the radiosurgical procedure and he remained seizure free at the 21-month follow-up with no new neurological or endocrine dysfunction. Twelve months after GKS, the hamartoma had completely disappeared.

In 2006, the group in Marseille published the longterm results of their prospective trial in which a total of 60 patients with $\mathrm{HH}$ and intractable epilepsy were enrolled. ${ }^{62}$ The median prescribed marginal dose was $17 \mathrm{~Gy}$ (range 13-26 Gy). The authors judiciously used a beamblocking strategy to reduce the dose delivered to critical surrounding structures such as the mammillary bodies, tuber cinereum, fornices, and infundibulum as well as op- 
tic nerves and chiasm. Thirty-one patients were evaluated for at least 3 years after radiosurgery; of these, satisfactory follow-up was available in 27. Only 10 (37\%) of these 27 patients achieved seizure freedom; 6 others (22\%) experienced a significant decrease in frequency of seizures. Although the majority had noteworthy improvement in behavior and cognition, the lesion appeared unchanged on follow-up MRI studies in most cases, except in 2 in which the hamartoma was slightly smaller. None of the patients had permanent complications from GKS; however, 4 (15\%) experienced transient worsening of seizures. The authors advocated that GKS should be regarded as primary treatment for small and medium HHs, whereas larger lesions should undergo a staged approach with microsurgical disconnection (open or endoscopic) of the lower part of the hamartoma followed by radiosurgical treatment of the small upper part of the residual $\mathrm{HH}^{62}$

Several other groups have reported their experience with GKS for treating intractable epilepsy related to HHs. , $7,16,17,31,38,73,75$ Taken together, these studies demonstrate that GKS is an effective treatment modality for selected patients with $\mathrm{HH}$-associated epilepsy. However, it is important to remember that, similar to the complications of microsurgical resection of the $\mathrm{HH}$, radiosurgery can result in permanent neurological sequelae. ${ }^{60,64}$ Also, there seems to be a dose-dependent response in which improved seizure control rates are attained with marginal doses $>16$ Gy. ${ }^{59}$ However, one of the main disadvantages is that clinical response can be very slow; the patient remains exposed to the risks of persistent seizures for up to 2 years after the radiosurgical procedure. In this regard, microsurgical resection has a clear advantage because of its ability to yield immediate postsurgical results.

\section{Linear Accelerator-Based Radiosurgery}

There have been fewer reports describing the use of LINAC-based SRS for treatment of HHs. As mentioned previously, in 2002 Akai et al. ${ }^{3}$ used radiosurgery to treat a 5-year-old girl with $\mathrm{HH}$-related gelastic seizures after neuroendoscopic biopsy of the hypothalamic mass. At 6 months her symptoms were unchanged, and the authors proceeded with endoscopic resection and laser thermocoagulation of the lesion, with good results. In 2005, Selch et al. ${ }^{72}$ used LINAC-based SRS to treat gelastic seizures caused by sessile HHs in 3 patients. They prescribed 1518 Gy at the $90 \%-95 \%$ isodose line. Two patients were seizure free at 15 and 17 months after radiosurgery, and 1 achieved an Engel Class II outcome at 9 months. None had any postradiosurgical complications. In 2008, Papayannis et al..$^{52}$ reported their experience with 4 patients with $\mathrm{HH}$ who were treated using a LINAC apparatus at doses between 12 and 18 Gy. None of the 4 patients had any meaningful clinical improvement.

\section{Stereotactic Brachytherapy}

A stereotactic brachytherapy approach in which ${ }^{125} \mathrm{I}$ seeds were used has been reported by Schulze-Bonhage and colleagues to achieve a highly focal, effective, and minimally invasive treatment option for patients with HHs.

In their most recent report, Schulze-Bonhage and co- workers $^{71}$ reported their cumulative experience with interstitial radiosurgery in 24 patients with a mean followup period of 12 months (range 3-60 months). All patients had intrahypothalamic hamartomas with a mean volume of $1.2 \mathrm{ml}$ (range $0.4-3.8 \mathrm{ml}$ ). Seven patients had CPP and 2 had polydactyly suggesting Pallister-Hall syndrome. The procedure was repeated in 13 patients due to inefficacy of the initial treatment after 1 year. The treatment dose was 60 Gy to the surface of the hamartoma, with a mean placement time of $25 \pm 6.7$ days. After treatment, $12.5 \%$ of patients became completely seizure free and $25 \%$ had nondisabling partial complex seizures. Four patients $(16.7 \%)$ had $>90 \%$ reduction in frequency and another $4(16.7 \%)$ experienced $>75 \%$ reduction. Seven patients $(29.2 \%)$ did not benefit from interstitial radiosurgery. Treatment effects occurred within 8 weeks.

Of the 13 patients who underwent reimplantation, only 1 continued to have seizures after the second implantation. All patients showed improvement in behavior and social skills. There was a reduction in the volume of $\mathrm{HH}$ in only 7 patients, which suggested that there was functional inactivation of the epileptogenic tissue without actual destruction. No perioperative morbidity was reported. Brain edema occurred in 5 patients, which subsequently resolved over the following few months. There was no evidence of hormonal disturbances; however, 4 patients experienced weight gain of 5-24 kg. There were no neurological or cognitive deficits following implantation. The authors remarked that the duration of epilepsy seemed longer in those patients with less improved outcome and cautioned that edema is more likely with larger lesions and with eccentric seed placement. These factors could increase the risk of neuropsychiatric deficits with implantation. They concluded that seizure control with interstitial radiosurgery may be inferior to microsurgery, but that there are fewer side effects associated with stereotactic brachytherapy. They observed that a better outcome was obtained in patients treated earlier in the course of their epilepsy.

A subset of patients with $\mathrm{HH}$ who present with a milder form of epilepsy and have less significant behavioral and/or cognitive comorbidities may perhaps benefit the most from a radiosurgical approach as their primary treatment modality. ${ }^{20}$ Certainly, with more experience and further refinement of selection criteria, SRS will have a central role in treatment algorithms for the management of HHs.

\section{Stereotactic Radiofrequency Ablation}

Lesioning of the hamartoma by using stereotactic radiofrequency thermocoagulation rather than a direct microsurgical or radiosurgical approach has been used in some centers. This procedure has been used to treat patients with a variety of conditions such as intractable pain, movement disorders, refractory epilepsy, and metastatic brain tumors. ${ }^{5,32,54,56}$

In 1999, Parrent ${ }^{53}$ reported on a patient who continued to have disabling seizures despite partial excision of the $\mathrm{HH}$, anterior temporal lobe resection, and orbitofrontal corticectomy. Later, stereotactic radiofrequency abla- 
tion of the $\mathrm{HH}$ was performed, resulting in progressive amelioration of the epileptic disorder during a 28-month follow-up.

In 2003, Kuzniecky and Guthrie ${ }^{33}$ presented their experience with 12 children in whom progressive epileptic encephalopathy related to an $\mathrm{HH}$ was treated using thermocoagulation alone $(n=4)$ or supplemented with endoscopic partial resection $(n=8)$. Three patients were seizure free at a mean follow-up of 27.3 months (range 18-40 months). Three others had $>90 \%$ reduction in seizure frequency at a mean follow-up of 51.6 months (range 36-70 months). Two developed transient neurological deficits including oculomotor palsy and memory loss. One child died as a result of brainstem infarction. The authors concluded that in patients with small HHs, stereotactic thermocoagulation is a viable option.

The most extensive experience using MRI-guided stereotactic radiofrequency thermocoagulation for epileptogenic HH comes from Japan. ${ }^{21,22,24,28}$ In their most recent paper, Kameyama et al. ${ }^{29}$ reviewed results from 25 consecutive patients with $\mathrm{HH}$ and gelastic seizures who were treated with radiofrequency thermocoagulation. They divided HHs into 3 types based on coronal MRI findings: intrahypothalamic, parahypothalamic, and mixed type. Complete seizure freedom was seen in 19 (76\%) of 25 patients over a mean follow-up of 2.3 years. Transient postoperative complications included hyperthermia, hyperphagia, hyponatremia, Horner syndrome, and short-term memory problems. Six patients in whom CPP was diagnosed preoperatively showed no change in their endocrine status and continued requiring gonadotropin-releasing hormone agonist treatment. All 10 patients who had behavior disturbances preoperatively showed complete resolution of their behavioral abnormalities following radiofrequency ablation.

Wang et al..$^{77}$ recently reported on a 22-year-old man with a small sessile intraventricular $\mathrm{HH}$ presenting with intractable gelastic seizures. A depth electrode was inserted after local sedation and intrahamartoma epileptiform discharges were captured. Following radiofrequency thermocoagulation of the $\mathrm{HH}$, he remained seizure free 12 months after surgery. Also, instead of ablating the $\mathrm{HH}$, de Almeida and colleagues ${ }^{13}$ reported on an 18-year-old man who underwent a stereotactic disconnection of the $\mathrm{HH}$, for which radiofrequency thermocoagulation was used. The procedure aimed at disconnecting the hamartoma from the hypothalamus, medial forebrain bundle, fasciculus princeps, and dorsal longitudinal fasciculus. These authors obtained a sustained improvement in seizure frequency and a reduction in aggressive behavior over a 2-year period.

Overall, radiofrequency ablation provides an effective, minimally invasive approach for the treatment of HHs. The results with stereotactic radiofrequency ablation, unlike with SRS, can be seen immediately following the procedure. However, drawbacks of the technique include inexact volume of tissue ablation and the need for multiple trajectories to treat larger hamartomas, thereby adding to the risk of injury to the surrounding neurovascular structures compared with a single pass.

\section{Deep Brain Stimulation}

The nondestructive and reversible nature of DBS has made it an attractive consideration for the surgical treatment of medically refractory epilepsy. Mechanistically, the rationale for the efficacy of DBS for epilepsy is similar to that seen with high-frequency stimulation for the treatment of movement disorders. ${ }^{34,70}$ The DBS treatment method is thought to impede seizure activity via long-term inactivation of neurons adjacent to electrodes following stimulation. This would presumptively result in an interruption of the pathological epileptogenic activity involving the classic circuit of Papez and associated neural sites. Thus far, only 3 groups have used this strategy to treat the devastating epileptic syndrome associated with HHs.

In 2004, Watts and coworkers ${ }^{78,79}$ reported, in abstract form, their experience in a patient who underwent direct implantation of a stimulating electrode into the $\mathrm{HH}$. Early results showed improvement in seizure activity and social/communication skills 7 months after surgery. Unfortunately, no follow-up report has been presented on this patient. More recently, Khan and colleagues ${ }^{30}$ described 2 patients with pharmacoresistant seizures due to $\mathrm{HH}$ who underwent DBS electrode placement adjacent to the ipsilateral mammillothalamic tract. Following highfrequency stimulation of the mammillothalamic tract, both patients experienced significant reduction in seizure frequency; one of them was seizure free for 10 months after surgery. Finally, Marras et al. ${ }^{37}$ reported their experience with DBS in a 31-year-old woman with $\mathrm{HH}$-related seizures. After 18 months, her complex partial seizures showed a decrease in frequency and intensity. However, there was no change in her overall seizure frequency (complex partial and gelastic seizures). No behavioral, endocrinological, or neurological side effects were noted. Certainly, further work needs to be done to determine the role of DBS in the treatment of epilepsy related to HHs.

\section{Vagal Nerve Stimulation}

Three groups reported their experience with a VNS for HH-related epilepsy. In 2000, Murphy et al. ${ }^{43}$ first reported using a VNS on the left side as primary treatment in 6 children with HHs. Three had some improvement but the other 3 did not respond. However, the conduct in all 4 children with severe autistic behavior improved after VNS implantation. Brandberg et al. ${ }^{8}$ implanted a VNS in 5 children; none had any clinical benefit. Finally, Watts and colleagues ${ }^{78}$ presented, in abstract form, two patients with $\mathrm{HH}$ who did not benefit from VNS therapy as either a primary or secondary procedure. We believe, as stated by Feiz-Erfan et al., ${ }^{18}$ that this palliative technique is not effective in controlling gelastic seizures, and therefore has a very limited role in the treatment of patients with $\mathrm{HH}$-associated gelastic seizures.

\section{Frontal or Temporal Corticectomy}

Seizure semiology generally evolves over time in patients with sessile HHs. A slow spike and wave pattern on 


\section{S. Mittal et al.}

scalp electroencephalograms, which is not uncommonly seen, is often related to development of focal motor features, autonomic phenomena, and secondary generalization including drop attacks. Some seizure types suggest that onset of seizures is in the temporal or frontal lobe. However, even in patients with depth electrode recording showing early involvement of the temporal or frontal region, resection of these cortical areas has invariably failed to control the seizures. ${ }^{11}$ Clearly the intrinsically epileptogenic hamartoma has to be addressed to achieve a good outcome.

\section{Corpus Callosotomy}

Corpus callosotomy is an effective palliative treatment for incapacitating generalized seizures including drop attacks. Unfortunately, anterior callosotomy had minimal benefit in improving the generalized seizure pattern in the 3 patients with $\mathrm{HH}$ who were so treated..$^{11,50}$ Thus, like VNS therapy, there appears to be a very limited role for corpus callosotomy in the management of disease in patients with HHs and disabling seizures.

\section{Combined/Staged Approaches and Repeat Surgery}

Patients with $\mathrm{HH}$ who have a catastrophic epileptic syndrome clearly benefit from neurosurgical treatment. As noted earlier, seizure freedom as well as improvement in both behavioral and neurocognitive deficits occurs in a significant number of patients following initial intervention. However, if disabling seizures persist or if behavior and cognition continue to decline, further medical management options remain limited. It is therefore essential to reevaluate patients with suboptimal results after initial surgery and determine if they could benefit from additional intervention. The Barrow group recently reviewed their experience with repeat surgery in 21 patients in whom the initial procedure failed. ${ }^{55}$ They noted that 14 patients had a $>50 \%$ reduction in seizures following reoperation, with minimal additional morbidity. Treatment options at second surgery can include any of the aforementioned approaches.

\section{Conclusions}

The treatment of HHs has evolved considerably over the past 2 decades. With proper understanding of the intrinsic epileptogenesis of the hamartoma, elegant approaches were developed, including microsurgical resection and/or disconnection. These techniques, directly targeting the $\mathrm{HH}$ itself, have yielded impressive surgical outcomes. Less invasive treatment modalities in which SRS was used have also been shown to have good outcomes in seizure control and improvements in behavior, cognition, and overall development. Younger patients in particular may benefit most from aggressive surgical management in an attempt to curtail or eliminate the behavioral and cognitive sequelae commonly associated with this debilitating subcortical epileptic syndrome. No single neurosurgical approach is likely to treat all forms of $\mathrm{HH}$ effectively. Rather, the precise surgical method must be carefully chosen based on important clinical and radiographic parameters. Occasionally, a multimodal or staged procedure must be used to address the lesion adequately. Indeed, a tailored approach based on patient age, size of the lesion, its attachment to the hypothalamus, and the experience of the treating physicians will provide the greatest likelihood of successful outcome.

\section{Disclosure}

The authors report no conflict of interest concerning the materials or methods used in this study or the findings specified in this paper.

Author contributions to the study and manuscript preparation include the following. Conception and design: S Mittal. Acquisition of data: all authors. Analysis and interpretation of data: S Mittal. Drafting the article: S Mittal, M Mittal. Critically revising the article: all authors. Reviewed submitted version of manuscript: all authors. Approved the final version of the manuscript on behalf of all authors: S Mittal. Administrative/technical/material support: S Mittal. Study supervision: S Mittal.

\section{Acknowledgment}

The authors thank Brandon J. Parker, M.P.A., for editorial assistance.

\section{References}

1. Abla AA, Rekate HL, Wilson DA, Wait SD, Uschold TD, Prenger E, et al: Orbitozygomatic resection for hypothalamic hamartoma and epilepsy: patient selection and outcome. Childs Nerv Syst 27:265-277, 2011

2. Abla AA, Shetter AG, Chang SW, Wait SD, Brachman DG, $\mathrm{Ng}$ YT, et al: Gamma Knife surgery for hypothalamic hamartomas and epilepsy: patient selection and outcomes. Clinical article. J Neurosurg 113 Suppl:207-214, 2010

3. Akai T, Okamoto K, Iizuka H, Kakinuma H, Nojima T: Treatments of hamartoma with neuroendoscopic surgery and stereotactic radiosurgery: a case report. Minim Invasive Neurosurg 45:235-239, 2002

4. Anderson JF, Rosenfeld JV: Long-term cognitive outcome after transcallosal resection of hypothalamic hamartoma in older adolescents and adults with gelastic seizures. Epilepsy Behav 18:81-87, 2010

5. Anzai Y, Lufkin R, DeSalles A, Hamilton DR, Farahani K, Black KL: Preliminary experience with MR-guided thermal ablation of brain tumors. AJNR Am J Neuroradiol 16:3952,1995

6. Arita K, Kurisu K, Iida K, Hanaya R, Akimitsu T, Hibino S, et al: Subsidence of seizure induced by stereotactic radiation in a patient with hypothalamic hamartoma. Case report. J Neurosurg 89:645-648, 1998

7. Barajas MA, Ramírez-Guzman MG, Rodríguez-Vázquez C, Toledo-Buenrostro V, Cuevas-Solórzano A, RodríguezHernández G: Gamma knife surgery for hypothalamic hamartomas accompanied by medically intractable epilepsy and precocious puberty: experience in Mexico. J Neurosurg 102 Suppl:53-55, 2005

8. Brandberg G, Raininko R, Eeg-Olofsson O: Hypothalamic hamartoma with gelastic seizures in Swedish children and adolescents. Eur J Paediatr Neurol 8:35-44, 2004

9. Bunyaratavej K, Locharernkul C, Tepmongkol S, Lerdlum S, Shuangshoti S, Khaoroptham S: Successful resection of Hypothalamic Hamartoma with intractable gelastic seizures-by transcallosal subchoroidal approach. J Med Assoc Thai 89: 1269-1276, 2006

10. Cappabianca P, Cinalli G, Gangemi M, Brunori A, Cavallo LM, de Divitiis E, et al: Application of neuroendoscopy to in- 
traventricular lesions. Neurosurgery 62 (Suppl 2):575-598, 2008

11. Cascino GD, Andermann F, Berkovic SF, Kuzniecky RI, Sharbrough FW, Keene DL, et al: Gelastic seizures and hypothalamic hamartomas: evaluation of patients undergoing chronic intracranial EEG monitoring and outcome of surgical treatment. Neurology 43:747-750, 1993

12. Choi JU, Yang KH, Kim TG, Chang JH, Chang JW, Lee BI, et al: Endoscopic disconnection for hypothalamic hamartoma with intractable seizure. Report of four cases. J Neurosurg 100 (5 Suppl Pediatrics):506-511, 2004

13. de Almeida AN, Fonoff ET, Ballester G, Teixeira MJ, Marino R Jr: Stereotactic disconnection of hypothalamic hamartoma to control seizure and behavior disturbance: case report and literature review. Neurosurg Rev 31:343-349, 2008

14. De Ribaupierre S, Delalande O: Hemispherotomy and other disconnective techniques. Neurosurg Focus 25(3):E14, 2008

15. Delalande O, Fohlen M: Disconnecting surgical treatment of hypothalamic hamartoma in children and adults with refractory epilepsy and proposal of a new classification. Neurol Med Chir (Tokyo) 43:61-68, 2003

16. Drees C, Chapman K, Prenger E, Baxter L, Maganti R, Rekate $\mathrm{H}$, et al: Seizure outcome and complications following hypothalamic hamartoma treatment in adults: endoscopic, open, and Gamma Knife procedures. Clinical article. J Neurosurg 117:255-261, 2012

17. Dunoyer C, Ragheb J, Resnick T, Alvarez L, Jayakar P, Altman $\mathrm{N}$, et al: The use of stereotactic radiosurgery to treat intractable childhood partial epilepsy. Epilepsia 43:292-300, 2002

18. Feiz-Erfan I, Horn EM, Rekate HL, Spetzler RF, Ng YT, Rosenfeld JV, et al: Surgical strategies for approaching hypothalamic hamartomas causing gelastic seizures in the pediatric population: transventricular compared with skull base approaches. J Neurosurg 103 (4 Suppl):325-332, 2005

19. Fohlen M, Lellouch A, Delalande O: Hypothalamic hamartoma with refractory epilepsy: surgical procedures and results in 18 patients. Epileptic Disord 5:267-273, 2003

20. Frazier JL, Goodwin CR, Ahn ES, Jallo GI: A review on the management of epilepsy associated with hypothalamic hamartomas. Childs Nerv Syst 25:423-432, 2009

21. Fujimoto Y, Kato A, Saitoh Y, Ninomiya H, Imai K, Hashimoto $\mathrm{N}$, et al: Open radiofrequency ablation for the management of intractable epilepsy associated with sessile hypothalamic hamartoma. Minim Invasive Neurosurg 48:132-135, 2005

22. Fujimoto Y, Kato A, Saitoh Y, Ninomiya H, Imai K, Sakakibara RI, et al: Stereotactic radiofrequency ablation for sessile hypothalamic hamartoma with an image fusion technique. Acta Neurochir (Wien) 145:697-701, 2003

23. Fujita T, Nishimura S, Sakata H, Furuno Y, Mino M, Hori E, et al: [A successful surgical case of a hypothalamic hamartoma with gelastic seizure: a case report.] No Shinkei Geka 37:781-785, 2009 (Jpn)

24. Fukuda M, Kameyama S, Wachi M, Tanaka R: Stereotaxy for hypothalamic hamartoma with intractable gelastic seizures: technical case report. Neurosurgery 44:1347-1350, 1999

25. Ghanta RK, Koti K, Kongara S, Meher GE: Surgical excision of hypothalamic hamartoma in a twenty months old boy with precocious puberty. Indian J Endocrinol Metab 15 (Suppl 3):S255-S258, 2011

26. Hamlat A, Morandi X, Riffaud L, Carsin-Nicol B, Haegelen $\mathrm{C}$, Helal H, et al: Transtemporal-transchoroidal approach and its transamygdala extension to the posterior chiasmatic cistern and diencephalo-mesencephalic lesions. Acta Neurochir (Wien) 150:317-328, 2008

27. Harvey AS, Freeman JL, Berkovic SF, Rosenfeld JV: Transcallosal resection of hypothalamic hamartomas in patients with intractable epilepsy. Epileptic Disord 5:257-265, 2003

28. Homma J, Kameyama S, Masuda H, Ueno T, Fujimoto A, Oishi M, et al: Stereotactic radiofrequency thermocoagulation for hypothalamic hamartoma with intractable gelastic seizures. Epilepsy Res 76:15-21, 2007

29. Kameyama S, Murakami H, Masuda H, Sugiyama I: Minimally invasive magnetic resonance imaging-guided stereotactic radiofrequency thermocoagulation for epileptogenic hypothalamic hamartomas. Neurosurgery 65:438-449, 2009

30. Khan S, Wright I, Javed S, Sharples P, Jardine P, Carter M, et al: High frequency stimulation of the mamillothalamic tract for the treatment of resistant seizures associated with hypothalamic hamartoma. Epilepsia 50:1608-1611, 2009

31. Kida Y, Yoshimoto M, Hasegawa T: [Radiosurgery of hypothalamic hamartomas.] No Shinkei Geka 36:225-232, 2008 (Jpn)

32. Kuzniecky R, Guthrie B, Mountz J, Bebin M, Faught E, Gilliam F, et al: Intrinsic epileptogenesis of hypothalamic hamartomas in gelastic epilepsy. Ann Neurol 42:60-67, 1997

33. Kuzniecky RI, Guthrie BL: Stereotactic surgical approach to hypothalamic hamartomas. Epileptic Disord 5:275-280, 2003

34. Lega BC, Halpern CH, Jaggi JL, Baltuch GH: Deep brain stimulation in the treatment of refractory epilepsy: update on current data and future directions. Neurobiol Dis 38:354360,2010

35. Likavec AM, Dickerman RD, Heiss JD, Liow K: Retrospective analysis of surgical treatment outcomes for gelastic seizures: a review of the literature. Seizure 9:204-207, 2000

36. Machado HR, Hoffman HJ, Hwang PA: Gelastic seizures treated by resection of a hypothalamic hamartoma. Childs Nerv Syst 7:462-465, 1991

37. Marras CE, Rizzi M, Villani F, Messina G, Deleo F, Cordella $\mathrm{R}$, et al: Deep brain stimulation for the treatment of drugrefractory epilepsy in a patient with a hypothalamic hamartoma. Case report. Neurosurg Focus 30(2):E4, 2011

38. Mathieu D, Kondziolka D, Niranjan A, Flickinger J, Lunsford LD: Gamma knife radiosurgery for refractory epilepsy caused by hypothalamic hamartomas. Stereotact Funct Neurosurg 84:82-87, 2006

39. Miller ML, Kaufman BA, Lew SM: Modified osteoplastic orbitozygomatic craniotomy in the pediatric population. Childs Nerv Syst 24:845-850, 2008

40. Miranda P, Esparza J, Cabrera A, Hinojosa J: Giant hypothalamic hamartoma operated through subfrontal approach with orbitary rim osteotomy. Pediatr Neurosurg 42:254-257, 2006

41. Mittal S, Mittal M, Montes JL, Farmer JP, Andermann F: Hypothalamic hamartomas. Part 1. Clinical, neuroimaging, and neurophysiological characteristics. Neurosurg Focus 34(6): E6, 2013

42. Mottolese C, Stan H, Bret P, Berlier P, Lapras C: Hypothalamic hamartoma: the role of surgery in a series of eight patients. Childs Nerv Syst 17:229-238, 2001

43. Murphy JV, Wheless JW, Schmoll CM: Left vagal nerve stimulation in six patients with hypothalamic hamartomas. Pediatr Neurol 23:167-168, 2000

44. Ng YT, Rekate HL, Prenger EC, Chung SS, Feiz-Erfan I, Wang NC, et al: Transcallosal resection of hypothalamic hamartoma for intractable epilepsy. Epilepsia 47:1192-1202, 2006

45. Ng YT, Rekate HL, Prenger EC, Wang NC, Chung SS, Feiz-Erfan I, et al: Endoscopic resection of hypothalamic hamartomas for refractory symptomatic epilepsy. Neurology 70:1543-1548, 2008

46. Nishio S, Fujiwara S, Aiko Y, Takeshita I, Fukui M: Hypothalamic hamartoma. Report of two cases. J Neurosurg 70: 640-645, 1989

47. Nishio S, Shigeto H, Fukui M: Hypothalamic hamartoma: the role of surgery. Neurosurg Rev 16:157-160, 1993

48. Northfield DW, Russell DS: Pubertas praecox due to hypothalamic hamartoma: report of two cases surviving surgical removal of the tumour. J Neurol Neurosurg Psychiatry 30: $166-173,1967$ 


\section{S. Mittal et al.}

49. Paillas JE, Roger J, Toga M, Soulayrol R, Salamon G, Dravet $\mathrm{C}$, et al: [Hamartoma of the hypothalamus. Clinical, radiological and histological study. Results of excision.] Rev Neurol (Paris) 120:177-194, 1969 (Fr)

50. Pallini R, Bozzini V, Colicchio G, Lauretti L, Scerrati M, Rossi GF: Callosotomy for generalized seizures associated with hypothalamic hamartoma. Neurol Res 15:139-141, 1993

51. Palmini A, Paglioli-Neto E, Montes J, Farmer JP: The treatment of patients with hypothalamic hamartomas, epilepsy and behavioural abnormalities: facts and hypotheses. Epileptic Disord 5:249-255, 2003

52. Papayannis CE, Consalvo D, Seifer G, Kauffman MA, Silva W, Kochen S: Clinical spectrum and difficulties in management of hypothalamic hamartoma in a developing country. Acta Neurol Scand 118:313-319, 2008

53. Parrent AG: Stereotactic radiofrequency ablation for the treatment of gelastic seizures associated with hypothalamic hamartoma. Case report. J Neurosurg 91:881-884, 1999

54. Parrent AG, Blume WT: Stereotactic amygdalohippocampotomy for the treatment of medial temporal lobe epilepsy. Epilepsia 40:1408-1416, 1999

55. Pati S, Abla AA, Rekate HL, Ng YT: Repeat surgery for hypothalamic hamartoma in refractory epilepsy. Neurosurg Focus 30(2):E3, 2011

56. Patil AA, Andrews R, Torkelson R: Stereotactic volumetric radiofrequency lesioning of intracranial structures for control of intractable seizures. Stereotact Funct Neurosurg 64:123133, 1995

57. Pendl G: Gelastic epilepsy in tumors of the hypothalamic region. Adv Neurosurg 3:442-449, 1975

58. Ponsot G, Diebler C, Plouin P, Nardou M, Dulac O, Chaussain JL, et al: [Hypothalamic hamartoma and gelastic crises. Apropos of 7 cases.] Arch Fr Pediatr 40:757-761, 1983 (Fr)

59. Quigg M, Barbaro NM: Stereotactic radiosurgery for treatment of epilepsy. Arch Neurol 65:177-183, 2008

60. Régis J, Arkha Y, Yomo S, Bartolomei F, Peragut JC, Chauvel P: [Radiosurgery for drug-resistant epilepsies: state of the art, results and perspectives.] Neurochirurgie 54:320-331, 2008 (Fr)

61. Régis J, Rey M, Bartolomei F, Vladyka V, Liscak R, Schröttner $\mathrm{O}$, et al: Gamma knife surgery in mesial temporal lobe epilepsy: a prospective multicenter study. Epilepsia 45:504-515, 2004

62. Régis J, Scavarda D, Tamura M, Nagayi M, Villeneuve N, Bartolomei F, et al: Epilepsy related to hypothalamic hamartomas: surgical management with special reference to gamma knife surgery. Childs Nerv Syst 22:881-895, 2006

63. Rekate HL, Feiz-Erfan I, Ng YT, Gonzalez LF, Kerrigan JF: Endoscopic surgery for hypothalamic hamartomas causing medically refractory gelastic epilepsy. Childs Nerv Syst 22: 874-880, 2006

64. Romanelli P, Muacevic A, Striano S: Radiosurgery for hypothalamic hamartomas. Neurosurg Focus 24(5):E9, 2008

65. Rosenfeld JV: The evolution of treatment for hypothalamic hamartoma: a personal odyssey. Neurosurg Focus 30(2):E1, 2011

66. Rosenfeld JV, Feiz-Erfan I: Hypothalamic hamartoma treatment: surgical resection with the transcallosal approach. Semin Pediatr Neurol 14:88-98, 2007

67. Rosenfeld JV, Freeman JL, Harvey AS: Operative technique: the anterior transcallosal transseptal interforniceal approach to the third ventricle and resection of hypothalamic hamartomas. J Clin Neurosci 11:738-744, 2004

68. Rosenfeld JV, Harvey AS, Wrennall J, Zacharin M, Berkovic SF: Transcallosal resection of hypothalamic hamartomas, with control of seizures, in children with gelastic epilepsy. Neurosurgery 48:108-118, 2001

69. Sato M, Ushio Y, Arita N, Mogami H: Hypothalamic hamartoma: report of two cases. Neurosurgery 16:198-206, 1985

70. Schulze-Bonhage A: Deep brain stimulation: a new approach to the treatment of epilepsy. Dtsch Arztebl Int 106:407-412, 2009

71. Schulze-Bonhage A, Trippel M, Wagner K, Bast T, Deimling FV, Ebner A, et al: Outcome and predictors of interstitial radiosurgery in the treatment of gelastic epilepsy. Neurology 71:277-282, 2008

72. Selch MT, Gorgulho A, Mattozo C, Solberg TD, Cabatan-Awang C, DeSalles AA: Linear accelerator stereotactic radiosurgery for the treatment of gelastic seizures due to hypothalamic hamartoma. Minim Invasive Neurosurg 48:310-314, 2005

73. Shim KW, Chang JH, Park YG, Kim HD, Choi JU, Kim DS: Treatment modality for intractable epilepsy in hypothalamic hamartomatous lesions. Neurosurgery 62:847-856, 2008

74. Stabell KE, Bakke SJ, Egge A: Cognitive and neurological sequelae after stereoendoscopic disconnection of a hypothalamic hamartoma. A case study. Epilepsy Behav 24:274-278, 2012

75. Unger F, Schröttner O, Feichtinger M, Bone G, Haselsberger K, Sutter B: Stereotactic radiosurgery for hypothalamic hamartomas. Acta Neurochir Suppl 84:57-63, 2002

76. Wait SD, Abla AA, Killory BD, Nakaji P, Rekate HL: Surgical approaches to hypothalamic hamartomas. Neurosurg Focus 30(2):E2, 2011

77. Wang W, Wang W, Guo X, Zeng Y, Jiang X: Hypothalamic hamartoma causing gelastic seizures treated with stereotactic radiofrequency thermocoagulation. Epileptic Disord 11: 333-338, 2009

78. Watts C, Chandler C, Polkey CE, et al: Medically refractory epilepsy associated with hypothalamic hamartomas can be improved by a variety of neurosurgical techniques. Br J Neurosurg 18:427, 2004 (Abstract)

79. Watts C, Polkey C, Mullatti N, Selway R: Medically refractory epilepsy associated with hypothalamic hamartomas can be significantly ameliorated using stereotactic neurosurgical techniques. J Neurol Neurosurg Psychiatry 75:1213, 2004 (Abstract)

80. Yao HX, Luo SQ, Ma ZY, Zhang YQ, Jia G: [Complications after transcallosal transseptal interforniceal resection of hypothalamic hamartoma: analysis of 37 cases.] Zhonghua Yi Xue Za Zhi 89:898-900, 2009 (Chinese)

Manuscript submitted February 12, 2013.

Accepted March 19, 2013.

Please include this information when citing this paper: DOI: 10.3171/2013.3.FOCUS1356.

Address correspondence to: Sandeep Mittal, M.D., F.R.C.S.C., Department of Neurosurgery, Wayne State University, 4160 John R Street, Suite 930, Detroit, Michigan 48201. email: smittal@med. wayne.edu. 